\title{
Correspondance
}

\section{Incomplete patient drug information still a problem}

Tn 2001, we published a letter criticizing the poor quality of drug information available to the Canadian public, ${ }^{1}$ using as an example cisapride, a drug that had been withdrawn from the market for safety reasons in August 2000. In response, an official from the Therapeutic Products Programme (now the Therapeutic Products Directorate) of Health Canada agreed on the need for high-quality written patient information but lamented Health Canada's lack of regulatory authority to ensure public access to such information; ${ }^{2}$ he also noted that an initiative was under way "to improve the format and content of product monographs and to make their contents available to the Canadian public."

Drug information for patients, approved by Health Canada and designated as part of the official product monograph, is published in the Compendium of Pharmaceuticals and Specialties $(C P S) .{ }^{3}$ The patient monograph is claimed to be a "direct equivalent of the prescribing information," and "contains information, in lay language, that is required by the patient for safe and effective use of the drug."

To assess the quality and usefulness of patient information appearing in the $C P S$, we compared the information in the nefazodone (Serzone) monograph intended for health care professionals ${ }^{4}$ with that contained in the patient monograph for the same drug, ${ }^{5}$ both published in the 2003 edition of the CPS. We looked for the most serious risk associated with the use of nefazodone and explicit instructions to be followed if specific adverse events were experienced. Nefazodone was withdrawn from the Canadian market in November 2003 because of hepatotoxicity. ${ }^{6}$

Nefazodone was approved for use in Canada in 1994. In 1999 the professional product monograph was amended to warn of hepatotoxicy, including increased liver enzymes, hepatitis, jaundice, liver failure, liver necrosis, liver damage and the possibility of liver transplantation or death. ${ }^{4}$ However, the patient monograph ${ }^{5}$ published in the 2003 CPS does not reflect the 1999 amendment to the professional monograph and remained unchanged from 1994 until the drug was removed from the market in November 2003. Patients were simply instructed to tell their physicians if they had a history of seizures, liver disease, or heart or blood pressure disorders.
The patient monograph contained no warning of potentially permanent or fatal liver toxicity. No information was provided to allow patients to identify early signs of liver toxicity, and explicit instructions on the steps to be taken if symptoms of liver toxicity developed were simply absent. ${ }^{5}$

The Serzone patient monograph illustrates the glacial pace of the Therapeutic Products Directorate, if there is any movement at all, toward improving patient access to useful, accurate drug information. Clearly, the Serzone patient monograph was incomplete and not a "direct equivalent of the prescribing information" for almost 4 years. Patients might rightfully assume that drug information approved by the government is all that is necessary to use a drug effectively and safely. If a patient makes such an assumption, then patient drug information that is incomplete is inherently misleading and dangerous.

\section{Sana R. Sukkari}

Oncology-Palliative Care Pharmacist

Joseph Brant Memorial Hospital

Burlington, Ont.

Larry D. Sasich

Public Citizen Health Research Group

Washington, DC 


\section{References}

1. Sukkari SR, Sasich LD. Cisapride and patient information leaflets [letter]. CMAJ 2001;164(9) 1276-8.

2. Peterson RG. Cisapride and patient information leaflets [letter]. CMA7 2001;164(9):1278-9.

3. Repchinsky C, editor-in-chief. Compendium of pharmaceuticals and specialties: the Canadian dru reference for health care professionals. Ottawa: Canadian Pharmacists Association; 2003.

4. Serzone-5HT2. In: Repchinsky C, editor-inchief. Compendium of pharmaceuticals and specialties: the Canadian drug reference for health care professionals. Ottawa: Canadian Pharmacists Association; 2003. p. 1562-5.

5. Serzone-5HT2. Information for the patient. In Repchinsky C, editor-in-chief. Compendium of pharmaceuticals and specialties: the Canadian drug reference for bealth care professionals. Ottawa: Canadian Pharmacists Association; 2003.p B256-7.

6. Choi S. Nefazodone (Serzone) withdrawn because of hepatotoxicity. CMA7 2003;169(11) 1187.

DOI:10.1503/cmaj.1040296

\section{[Dr. Peterson responds:]}

$\mathrm{T}$ raditionally, physicians and pharmacists have interpreted for patients the technical prescribing information provided by drug manufacturers and approved by Health Canada. More recently, it has become apparent that manufacturers should be providing information more oriented to consumers, to bridge the gap between the technical product monograph and information needed by patients. As a result, a new section of the product monograph, entitled "Information for the Consumer," is required for all new submissions filed with Health Canada as of October 2004

With regard to the situation raised by Sana Sukkari and Larry Sasich, in 1999 Health Canada notified health care providers, through its Canadian Adverse Reaction Newsletter, of 9 cases of hepatic dysfunction in Canada among patients receiving Serzone. ${ }^{1}$ In July 2001, Health Canada issued an advisory on the risk of severe hepatic injury with Serzone. ${ }^{2}$

The product monograph for Serzone was updated in October 2001 to warn of potential hepatoxicity. This update included a warning to patients that Serzone had been associated with very rare cases of severe liver damage. It advised patients being treated with the drug to seek immediate medical attention if they experienced any of the symptoms on the list provided.
Health Canada reviews and authorizies updates to product monographs and patient information for drugs sold in Canada, and drug manufacturers have a responsibility to ensure that the most recent versions of these documents are released to health care professionals. It appears, for reasons unknown to Health Canada, that the changes made to the 2001 product monograph and information to the consumer were not transmitted for the 2002 and 2003 editions of the Compendium of Pharmaceuticals and Specialties. The product was withdrawn from the Canadian market in 2003.

Health Canada continues to pursue initiatives to make product monographs, including information for the consumer, more readily available to the Canadian public. Certainly, the number of notifications to health care professionals about important safety issues via the Health Canada Web site (www .hc-sc.gc.ca/english/protection/warnings .html) and mailings - reflects the need for physicians and pharmacists to remain current with respect to the drugs they prescribe and dispense.

\section{Robert G. Peterson}

Director General

Therapeutic Products Directorate

Health Products and Food Branch

Health Canada

Ottawa, Ont.

\section{References}

1. Hepatotoxicity associated with nefazodone (Serzone). Can Adverse React Newsl [serial online] 1999;9(3). Available: www.hc-sc.gc.ca/hpfb-dgpsa /tpd-dpt/adrv9n3_e.html\#NEFAZODONE (accessed 2004 Oct 4).

2. Risk of severe liver injury associated with use of the antidepressant nefazodone [advisory]. Ottawa: Health Canada; updated 2001 Jul 9. Available: www.hcsc.gc.ca/english/protection/warnings/2001/2001 74e.htm (accessed 2004 Oct 4)

DOI:10.1503/cmaj.1041448

\section{Catering to the customers}

T $\mathrm{t}$ is not surprising that 6 English-language journals published in North America and the United Kingdom would tend to include articles on topics of interest to English-speaking patients, physicians and researchers in those in- dustrialized, relatively wealthy countries, as reported by Paula Rochon and associates. ${ }^{1}$ Grant funding and the subsequent generation of manuscripts, driven by public and political advocacy and commercial interests, probably reinforce this practice.

This is not necessarily good or bad; it is simply a reflection of the professional interests of the readers. One could argue that these journals survive by focusing the bulk of their output on topics that are of interest to the subscribers and advertisers that generate their revenue streams — that's just good business practice.

The conduct and dissemination of a greater number of randomized controlled trials focused on world health priorities may ultimately depend on the development of a comparable research and publishing infrastructure in those less affluent countries, admittedly a daunting task.

\section{Louis B. Jacques}

Faculty

Georgetown University

Washington, DC

\section{Reference}

1. Rochon PA, Mashari A, Cohen A, Misra A, Laxer D, Streiner DL, et al. Relation between randomized controlled trials published in leading general medical journals and the global burden of disease. CMA7 2004;170(11):1673-7.

DOI:10.1503/cmaj.1040968

\section{[Three of the authors respond:]}

ometimes, it is important to state the obvious, even if it is not surprising. In our study ${ }^{1}$ we document that trials published in the leading general medical journals do not reflect the conditions and diseases that are the most important causes of death and disability internationally. Our study points out again the discrepancy between what has priority in North America relative to what is important for most people worldwide.

Even if a problem is obvious, it must sometimes be quantified before the medical community accepts it as a real and pressing issue. Putting numbers to an obvious issue somehow lends it credibility.

We hope our study will have other ef- 